PAPER

\title{
'Autism and the good life': a new approach to the study of well-being
}

\author{
Raffaele Rodogno, ${ }^{1}$ Katrine Krause-Jensen, ${ }^{1}$ Richard E Ashcroft ${ }^{2}$
}

${ }^{1}$ Department of Philosophy \& History of Ideas, Aarhus University, Aarhus C, Denmark ${ }^{2}$ School of Law, Queen Mary University of London, London, UK

\section{Correspondence to}

Dr Katrine Krause-Jensen; filkjj@cas.au.dk

Received 1 February 2016 Accepted 18 April 2016

\section{To cite: Rodogno $R_{\text {, }}$ Krause-Jensen $\mathrm{K}$, Ashcroft RE. J Med Ethics Published Online First: [please include Day Month Year] doi:10.1136/ medethics-2016-103595}

\section{ABSTRACT}

Medical, psychological, educational and social interventions to modify the behaviour of autistic people are only justified if they confer benefit on those people. However, it is not clear how 'benefit' should be understood. Most such interventions are justified by referring to the prospect that they will effect lasting improvements in the well-being and happiness of autistic people, so they can lead good lives. What does a good life for an autistic person consist in? Can we assume that his or her well-being is substantively the same as the well-being of non-autistic individuals? In this paper, we argue that, as it stands, the current approach to the study of well-being is for the most part unable to answer these questions. In particular, much effort is needed in order to improve the epistemology of wellbeing, especially so if we wish this epistemology to be 'autism-sensitive'. Towards the end of the paper, we sketch a new, autism-sensitive approach and apply it in order to begin answering our initial questions.

\section{INTRODUCTION}

In this paper, we examine the role of theories of well-being in justifying interventions intended to modify the behaviour of autistic people, especially those delivered by or on behalf of parents raising autistic children. ${ }^{i}$ The question of what gives autistic lives value is much discussed currently, in academic, policy and public contexts, and increasingly the voices of autistic people themselves are achieving prominence. At the heart of these discussions are difficult controversies about who has a say in defining well-being, about how far interventions should aim at 'normalising' the behaviour of autistic people and about trade-offs between short-term and long-term benefits, especially where interventions are seen to involve both benefits and harms to autistic people.

We are writing as ourselves parents of autistic children, who have wrestled with these issues personally as well as philosophically. Actively thinking about well-being from our role as parents, as well as academic philosophers, affords an entry point to the study of well-being that is rather untrodden. We ask questions about well-being from the point of view of a practice, that is, parenting children with autism, centrally animated by the concept of well-

${ }^{\mathrm{i}}$ We should note that we do not consistently refer to 'autistic people' or 'people with autism': there is a current controversy about which usage is preferable, which for reasons of space we take no stance on here, and instead try to use both variants without implying a preference. being. We claim that this practice-based approach enables us to ask the important questions about well-being that are at issue in this paper, to show why the current philosophical approach to the study of well-being cannot answer these questions and to explain how this approach can be amended so as to be able to address these questions.

Finally, while in this paper we focus on autism, we should like to think autism as a 'case study' of sorts for a broader claim, namely that a credible account of well-being will take into account neurodiversity.

\section{WELL-BEING IN PRACTICE}

Considerations of well-being confront us in a number of different ways and in a number of everyday contexts and practices. A paradigmatic case here is friendship. It is typical of at least some practices of friendship to enquire about one's friend's well-being. 'How are you?' we may ask our friend with some concern, or we may ask of a mutual acquaintance, 'How is she doing these days?' Sometimes, it is not even necessary to ask. We simply pick up from her looks, her behaviour or her reactions how well or badly a person is doing. Our everyday interest in well-being does not of course limit itself to our friends' well-being. We may, for one, be interested in our own well-being, or in that of our children, or, according to the social roles that we may happen to occupy, in the well-being of our students, our patients, our employees or the members of our constituency.

The specific roles or practices that we enact make relevant certain aspects of well-being rather than others and direct our attention towards them. ${ }^{\mathrm{i}}$ Hence, the quality and intensity of a patient's pain, what conditions this pain may indicate and what activities this pain may impede may prompt a doctor to recommend surgical intervention. Similarly, a politician should be interested in those aspects of citizens' well-being, such as safety in the streets and levels of public health provisions that are considered to be the proper object of political action. ${ }^{\text {iii }}$

A couple of important features can be read off from these examples of everyday practices. First, they are action-oriented or practical. Hence, your

\footnotetext{
${ }^{\text {ii }}$ See Rodogno ${ }^{1}$ ( $\left.\mathrm{p} 50-55\right)$ for a discussion of the notion of an aspect of well-being.

iiiThough, of course, some will dispute that such considerations are ultimately relevant to political action in connection to citizens' well-being as much as they are relevant in connection to their rights and freedoms.
} 
interest in your friend's well-being is typically accompanied by some preparedness on your behalf to help her, if that were indeed necessary and appropriate. If you systematically failed to be motivated to do so, it would be legitimate for someone to doubt the authenticity of your friendship. Second, the scope and nature of well-being interventions, and, hence the aspects of well-being that are taken to be the relevant targets of intervention, are at least in part determined by the nature of the practice in its cultural declinations. Hence, the fact that autonomy is highly valued in a certain cultural context places limits on what courses of action are considered as appropriate forms of helping one's friends in that context. On many occasions, it may turn out that the best thing for you to do is simply to 'be there for your friend' and offer moral support rather than actively changing his or her life.

The starting point of this paper, and, in fact, the experience that has quite literally started our recent thinking on this topic, is another well-being-centred practice, namely parenting and, in particular, the parenting of autistic children. In what follows, we will not say much about either parenting as such, or about the parenting of autistic children in particular. We believe, however, that the latter experience has been instrumental in gaining an external perspective on how well-being is typically studied in philosophical practice. From this perspective, we uncovered some of the hidden assumptions that regulate this practice and, as we hope to show, were somewhat able to correct for some of its blind spots. This is ultimately instrumental for both the study of well-being and autism and the study of well-being tout court.

For our purposes, let us agree that children's well-being does play a central role in our parenting practices, where this claim is to be articulated as follows. When choosing on behalf of their children, parents usually choose with their children's present and future well-being in view, with the aim of equipping them with whatever skills are most useful for living a good life, and the deep-seated hope that they will have a good life. When parents choose with apparent disregard for their children's wellbeing, it would be legitimate to call upon them to justify their choice. Only weightier moral reasons, necessity or justifiable ignorance are considered as good justifications. The claim is not that the child's well-being is the only norm regulating parenting but that it is a fundamental norm. Sure enough, most parents also want their children to grow up into (morally) good people but they will at the same time hope that their children have lives in which being good does not come in deep or systematic conflict with their well-being.

But what does the well-being that parents have in view when they choose on behalf of their children exactly consist in? We wonder how many parents have asked themselves this question or, perhaps more moderately, how many parents have asked themselves this question and found answers that involved changing much to what they were already doing in connection with their parenting. This should not necessarily be interpreted as a critical remark. Whether correct or otherwise, for all we know, most parents may typically take themselves to be doing whatever any parent ought to be doing, where this involves heavily relying on social structures, such as schools, religious organisations and those organisations that provide security and economic opportunities, as well as those practices, such as etiquette, that are meant to socialise one's child.

Whatever the context, the question still remains: what do these parents actually take good lives, the lives they wish their children to have, to consist in? Unfortunately, we do not have an answer to this question because no systematic (and crosscultural) effort to collect this type of information has, to our knowledge, been made, and because, as suggested above, there may well be no articulated answer to this question in the first place: many parents simply follow whatever positive practices and rely on whatever structures are in place in their society without much further thought.

From our experience as parents and individuals who talk to other parents, however, we can easily imagine that in modern societies, at least some parents adopt for their children some rather open-ended models of the good life. On these models, what parents wish for their children is often that they 'find happiness', where this would typically be found in having an interesting and well-remunerated job, good friends, a loving partner with whom to start a family, and in having a life free from debilitating sickness and long enough to enjoy one's grandchildren. Let us call this model the Standard Model and hope that it does indeed capture the view of many, if not most, people in this context.

Just as inhabiting a poverty-stricken or war-stricken society may lead some parents no longer to rely on the (quickly disappearing or inexistent) structures and possibilities afforded by their society, while at the same time holding on to whatever model of the good life they may have had, parenting a child with autism may lead parents to question whatever model of the good life they may have had and, thereby, those structures and practices in one's society whose point could be taken to be, entirely or in part, the realisation of this model.

To illustrate, consider how children with autism (but not only them) often engage in self-stimulatory behaviour (or 'stimming' as it is sometimes referred to), that is, repetitive body movements or repetitive movements of objects. The former may include rocking back and forth, hand-flapping, humming and grunting, echolalia and repeating portions of videos, books or songs at inappropriate times. The latter may include turning on and off light switches. Clearly many of these behaviours will be considered as inappropriate, if not disruptive, in many contexts and, importantly, in those contexts such as schools, in which children are supposedly building up skills instrumental to their future well-being. What is more, such behaviours will typically lead to stigmatisation. Letting the child freely enact them will in the end lead to his or her social isolation, a lack of training of those social skills that may already be in deficit in the autistic child and ultimately to lowering his or her current and future opportunities to enjoy many of the goods on the Standard Model.

Some of these behaviours may perhaps be trained away. Training, however, comes at a cost in terms of the current wellbeing of the child, for any time spent training such behaviours away is time that might have been used on activities of greater immediate benefit to the child. This trade-off is even more momentous in the case of autism when we consider that training some of these behaviours away may be a particularly difficult and long process. Even more importantly, however, it is by no means clear that training these traits away is of longer-term benefit to the autistic child. It may therefore be completely misguided to conceptualise the situation as a trade-off, less immediate well-being in favour of greater longer-term well-being. Whether there would be any reason to do so depends on whether we could safely assume that the Standard Model, or something sufficiently similar to it, could apply to adults with autism as well as neurotypicals.

We doubt that this assumption can safely be made. Consider, for one, what Jim Sinclair, a well-known autism-rights activist and himself autistic, has to say:

Autism is a way of being. It is pervasive; it colors every experience, every sensation, perception, thought, emotion, and encounter, every aspect of existence. It is not possible to separate the 
autism from the person--and if it were possible, the person you'd have left would not be the same person you started with. ${ }^{\text {iv }}$

Within the autism community, this is not an isolated view. Reading autobiographies by autistic individuals, browsing relevant websites such as wrongplanet.net or autreat.com and interacting with autistic people at the network meetings we organise $\mathrm{e}^{\mathrm{v}}$ only confirms that this view is indeed common. For our purposes, however, the next passage is even more revealing. As Sinclair tackles the question of 'normal' parent-to-autistic child relations, he writes:

You try to relate as parent to child, using your own understanding of normal children, your own feelings about parenthood, your own experiences and intuitions about relationships. And the child doesn't respond in any way you can recognize as being part of that system.

That does not mean the child is incapable of relating at all. It only means you're assuming a shared system, a shared understanding of signals and meanings, that the child in fact does not share. It's as if you tried to have an intimate conversation with someone who has no comprehension of your language. Of course the person won't understand what you're talking about, won't respond in the way you expect, and may well find the whole interaction confusing and unpleasant.

It takes more work to communicate with someone whose native language isn't the same as yours. And autism goes deeper than language and culture; autistic people are 'foreigners' in any society. You're going to have to give up your assumptions about shared meanings. You're going to have to learn to back up to levels more basic than you've probably thought about before, to translate, and to check to make sure your translations are understood. You're going to have to give up the certainty that comes of being on your own familiar territory, of knowing you're in charge, and let your child teach you a little of her language, guide you a little way into his world. ${ }^{\mathrm{vi}}$

We think there may be something worthy of further articulation in Sinclair's idea that 'autism goes deeper than language and culture', which can in fact be grasped by returning to the idea of the pervasiveness of autism. Different cultures may well fail to have a shared language and shared meanings. Yet the ethnographers that do field work on different cultures work from the assumption that the individuals they observe, at some basic psychological level, function just like anybody else. No matter how much culture can colour our perceptions and conceptual schemes, these will be built on psychological bases that are pretty much assumed to be pan-human. We know today that this assumption is only partly true. There may be genetic differences among populations that influence the working of the brain as well as cultural influences that in turn affect our neuropsychology. ${ }^{\text {vii }}$ Autism, however, introduces neuropsychological differences that go well beyond, or 'deeper' than, the differences in language and meaning that ethnographers may expect to encounter. $^{\text {viii }}$

\footnotetext{
${ }^{\text {iv Sinclair. }}{ }^{2}$ With fellow autistics Kathy Lissner Grant and Donna Williams, Jim Sinclair formed Autism Network International (ANI) in 1992, the first online network of this kind. Many thanks to Felix Munch for the reference and for the many insights into autism.

vodogno is co-founder and co-director of autism@aarbus, a network whose purpose is to abridge the distance between autism research and autism communities.

${ }^{\text {vi }}$ Sinclair. ${ }^{2}$

${ }^{v i i}$ See Han $e t a l .^{3}$ for a recent critical review of Cultural Neuroscience.

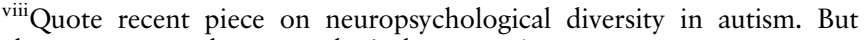
also some more phenomenological accounts?
}

Now if being autistic is so pervasive and to some extent foreign to 'normal' perspectives, it can only be wise to approach the question of autism and well-being with epistemic humility, that is, by suspecting that a good autistic life may not necessarily consist in the same things as it does for neurotypical individuals. At that point, however, some difficult questions arise: What does a good life, or the best possible life, for an individual with autism consist in? And how do we go about answering that question? Should we take our start from neurotypical models and then add and subtract features and goods? If so, by way of what criteria? Should we find common denominators, say, pleasure and pain, and assume that at bottom these are the things that matter prudentially to everyone?

Besides being important practical questions for some parents and their children, these are also philosophical questions. We may therefore want to turn to philosophy in search of an answer, but, alas, to no much avail. In what follows, we will briefly elucidate why current philosophical practice cannot as it stands offer much help with regard to these questions and indicate some of the directions that the study of well-being should take in order to find some answers.

\section{THE LIMITS OF THE CURRENT PHILOSOPHY OF WELL-BEING}

Current philosophical theories of well-being such as hedonism, desire satisfaction theory, objective list theories and perfectionism share the same underlying method or approach. In this section, we sketch this approach and then find fault with it. Our concern is not with these theories themselves, but with a specific step in their approach that betrays a lack of sensitivity to the particular issues that the case of autism brings to the table. This is to say that any of these theories may in principle be correct if and when the relevant methodological faults were redressed, and in the section following this one, we propose one way of doing just that.

Philosophical theorising on well-being can be viewed as a three-step process. Step 1 consists in bringing forth the data that the theory is then to systematise. While some philosophers make this step quite explicit, think, for example, about Aristotle's review of the endoxa in Book I Chapter 5 of the Nicomachean Ethics ${ }^{\text {ix }}$ or Wayne Sumner's reference to core and peripheral 'pre-theoretical beliefs' or 'pre-analytic convictions' about well-being, most philosophers simply take some data for granted. ${ }^{\mathrm{x}}$ The data, then, consist in pre-theoretical ideas and intuitions about the goods to be had in certain ways of life or the substantive sources of well-being, that is, kinds of experiences, of interactions and conditions of one's life (eg, eating a good meal, having a family, doing sport, reading novels, meeting with friends, having an interesting job, helping others, climbing a mountain, achieving recognition in some field) that are believed by the theorists to capture both common sense as well as, perhaps, more considered views about this topic.

Step 2 consists in constructing categories, or categorial goods, out of the data selected in step 1 . The outcome of this step is generally a list of potential substantive goods that typically includes pleasure and the absence of pain, achievement, virtue, autonomy, deep personal relations, meaningful knowledge and understanding, aesthetic appreciation, happiness and rational activity. For example, it may be that sources of well-being such

\footnotetext{
${ }^{i x}$ Aristotle (ref. 4 pp. 1731-1732).

${ }^{\mathrm{x}}$ Sumner (ref. 5 pp. 10-20). See also Haybron (ref. 6, Ch.1) for a richer description of current methodology in the philosophy of well-being.
} 
as eating a good meal and reading a good novel should be considered here under the category of pleasure (and the absence of pain).

Step 3 may take different forms depending on the theorist's leanings and it is at this point that different kinds of theory take shape. Most broadly two kinds of theories are put forward: substantive and formal. Substantive theories aim at enumerating the ultimate prudential goods. In practice, much of the argument among substantive theorists is an exchange between hedonism, that is, the view that pleasure or enjoyment is the only categorial good, on the one hand, and Objective List theories, that is, views according to which there are a number of irreducible prudential goods, on the other. ${ }^{\mathrm{xi}}$

The aim of formal theories is to identify the one property that all the goods from step 2, and in fact, all the sources of well-being identified in step 1 have in common, or, perhaps, ought on reflection to have in common. Formal theories will in other words explain why or in virtue of what something is indeed a prudential good. Hence, on desire fulfilment views, what makes pleasant states or activities good for you is ultimately the fact that you desire them (or would desire them if rationale). Similarly, for some perfectionists only those activities that perfect human nature are to count as good for us.

It is at this point useful to illustrate the way in which philosophers argue for one theory as opposed to the other and, hence, the structure of their disagreement. Ideally, formal and substantive disagreements will be straightened out in reflective equilibrium. That is, our theories of well-being will converge as the inferences we can draw from them are made to cohere with our considered judgements and deeply held intuitions about wellbeing. The problem, however, is that there are fundamental disagreements about a number of deeply held intuitions about well-being. Hence, for example, while some take well-being to be essentially or conceptually subjective, others do not. ${ }^{\text {xii }}$ Similarly, while some take well-being to be essentially or conceptually mentalistic, others do not. ${ }^{\text {xiii }}$ Finally, some philosophers enter the discussion with very firm intuitions about the scope of the concept of well-being. Hence, for example, cases in which we seriously compromise our health, our ambitions and even our life for the sake of someone else are portrayed as by definition cases in which we sacrifice our well-being. ${ }^{\text {xiv }}$ If on a given theory of well-being the option that seems intuitively to be selfsacrificial is described as the better option for the agent, then that theory is to be rejected as having a 'scope problem', that is, as extending the idea of well-being to conceptual spaces that are beyond its intuitive scope.

These dialectics are important to our present purposes as they reveal how philosophers enter the study of well-being with predetermined substantive and conceptual ideas about well-being. Substantively, their theories can only systematise whatever material is taken to be relevant in the first place, that is, in step 1 . What is more, some philosophers will only take some of this initial

\footnotetext{
${ }^{x i}$ Those who defend Objective List theories disagree about what the goods on the list are. See Fltecher (ref. 7, p. 149) for a quick comparison of different objective lists.

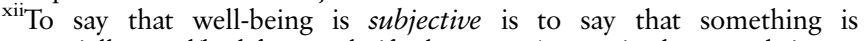
potentially good/bad for $x$ only if $x$ has a pro/con attitude towards it.

${ }^{x i i i}$ Mentalism about well-being involves the belief that only mental states (that subjects are conscious or aware of) can potentially contribute to well-being.

${ }^{\text {xiv }}$ See Darwall's discussion of Tarzan's decision to leave Jane with Clayton (ref. 8, pp. 22-25) and his discussion of the Sheila example (2002, pp. 43-49).
}

material to be relevant in accordance to abstract conceptual requirements, such as subjectivism and mentalism. ${ }^{\mathrm{xv}}$ This explains why current philosophy is of little help in answering the questions that concern us. The autistic perspective is simply absent from the start and hence not systematised into theory. In order to include this perspective, we would have to be in possession of common sense and, perhaps, considered judgements about what kinds of activities or states are good and bad for individuals with autism. Or, to put it in the language of the philosophers, we would have to have 'pre-theoretical beliefs' or 'intuitions' about autistic wellbeing be they 'central' or 'peripheral'; or again, we would have to be in possession of the relevant endoxa. But this is precisely what we were lacking and why we turned to the philosophy of wellbeing in the first instance.

Any attempt to incorporate the autistic perspective into the current philosophical approach raises some fundamental questions about the approach itself, not only in its application to the autism case, but in its ordinary employment. Consider what incorporating this perspective would require. We would need to understand what kind of things, events, feelings, activities or pursuits, persons, and so on make a positive contribution to the lives of individuals with autism and what kinds of things do not. On the current approach, this information would form the basis of step 1. But how does one get this information in the case of autism or in the case of neurodiversity more in general? And, in fact, how does one gather this information in the standard case?

In other words, by what processes do we come to form 'pretheoretical beliefs' or 'intuitions' about well-being or the relevant Aristotelian endoxa? This is a basic but neglected epistemological question. While we would not be able to say what the dominant philosophical stance on this issue would be, we do suspect that a number of different stances would be defended. While at one hand of the spectrum we would expect some philosophers to call forth the idea that these intuitions and beliefs are a priori, at the other hand of the spectrum, we would expect empiricist answers such as J.S. Mill's according to whom the only evidence we have that something is good for us is the fact that we desire it. ${ }^{\text {xvi }}$

The case of autism suggests that the information that constitutes this first step is not something we can simply assume but rather something that needs to be carefully collected. Given the neurodiversity involved by autism, we cannot simply rely on assumptions about 'people's pre-reflective intuitions' on wellbeing or on what we think people typically desire, not even when these intuitions and desires are refined by way of reflection and rational exchange. Much more work than usually suspected goes into collecting these data, and, what is more, this work raises a number of difficult methodological and epistemological questions:

How do we gather this information? Do we literally ask people with autism? Given the diversity of people on the autistic spectrum, are there some individuals that are more representative than others and whose views should be given more weight? If we decide to ask people with autism, what exactly would we be asking and with what wording? How do we make sure that the

\footnotetext{
${ }^{\mathrm{xv}} \mathrm{It}$ is in turn interesting to know how these conceptual requirements enter the picture. Are these linguistic intuitions that philosophers have on the basis of (extrapolate from exposure to) certain substantive views of well-being or are they supposed to arise independently of the latter but by contrasting the role that the concept of well-being or prudential goodness plays in language with concepts in its vicinity such as moral goodness and perfection?

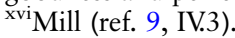


question is not skewed, i.e., a question more appropriately to be asked to neurotypicals? What about those who cannot express themselves? Would it be legitimate to ask the relevant question/s to those who take care of them instead or would that reintroduce an illegitimate neurotypical perspective? Should our method be quantitative or qualitative? Should we rather/also employ ethnographic methods involving observation and interpretation? Should the ethnographer herself be autistic? What is the ethnographer to take as evidence that the presence of a certain person, activity, feeling, state, etc., in a person's life is good/bad for that person?

These are difficult methodological questions, which cannot properly be treated in a short space. In what follows, we will, however, sketch a proposal, not so much as an ultimate solution but as a contender eventually to be tested against others, which will answer some of these questions. ${ }^{\text {xvii }}$

\section{SKETCHING A NEW APPROACH}

As presented above, the current approach ultimately aims at providing answers to distinct though connected kinds of questions, namely what kind of things are ultimate prudential goods and why, or in virtue of what, are these things prudential goods. Let us call these questions prudential questions. Our initial question is quite different from this and more directly action-oriented. We are looking to understand what model/s of the good life, if any, those who take care of autistic individual should employ in order to orient their well-being interventions. The prudential question and the action-oriented question, however, are connected, for, presumably, models of the good life may be informed by theoretical reflection of the prudential kind. Hence, one may, for example, maintain that the good life will be the one that contains the right balance of those ultimate goods specified in one's Objective List.

Yet, as argued above, the current approach cannot as it stands afford an answer to our practical question. The problem lies in step 1 and is an epistemological one. We must gather autismrelevant information about well-being and ill-being and there are difficult questions concerning how to go about doing that. We also argued that on the current approach this is not simply a problem connected to the case of autism but one that affects the study of well-being in general. The disagreements among theories of well-being at the level of step 3 are ultimately based on fundamental substantive and conceptual disagreements that go back to step 1. In what follows, then, we will propose a new general epistemology of well-being, which, with some caveats, can ultimately be applied to the case of autism and hence be used to answer our initial question.

In line with the approach sketched in section 'Well-being in practice', we claim that well-being is best studied in its context, that is, those everyday practices that it animates. In these contexts, we are typically concerned with whether this or that person is doing well or badly, with the possibility of action or intervention in view. Figuring out how well someone is doing is, at least initially, a different exercise from asking the rather more abstract prudential questions presented in the previous section, which are the philosophers' typical entry point in this discussion.

Now on the practice-based approach, in order to understand how well a person is doing, we need next to answer an epistemological question: what kind of information is to count as

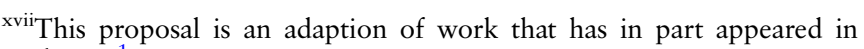
Rodogno. ${ }^{1}$ evidence that someone is doing well or badly? As argued elsewhere ${ }^{10}$ on one interpretation of the relevant practices, we should take happiness and unhappiness to be our main epistemic channel to answer to our well-being question.

This clearly requires defending an account of happiness. On the one endorsed here, happiness is an emotional condition very much in line with Dan Haybron's idea of psychic flourishing. ${ }^{\text {xviii }}$ Happiness is here to be understood as being made up of two components, namely central affective states, as opposed to peripheral ones; and a person's mood propensity, or disposition to experience moods. To elaborate: while peripheral effect includes purely physical, seemingly emotionless pleasures and pains-an itch, eating a cracker, seeing an attractive building, noting with approval that some distant stranger got rich in the lottery-central affective states include moods (eg, anxiety) and mood-constituting emotions (eg, sadness and joy). The idea of a mood propensity may be illustrated by the case of an emotionally fragile widow who, while quite cheerful at the moment, may easily and somewhat unexpectedly break down into tears. In short, happiness on such view is more nearly the opposite of depression, anxiety and irritability, whereas hedonistic happiness is simply opposed to pleasantness.

The central affective states involved in happiness consist rather in three different modes of response, corresponding to different types of evaluations. At the most basic level, there are states of tranquillity versus anxiety. The root idea here concerns being psychically at home or secure in one's life. Haybron calls this dimension of happiness attunement. Assuming one's situation is secure, the next question is whether it merits investment or effort. There are two sorts of positive response here: vitality and flow, where the latter is opposed to boredom, and the former involves a state of energy or enthusiasm. This dimension of happiness is here called engagement. Those who are depressed, besides being sad, lack precisely the type of hearty engagement with their life described here. They are disengaged and withdrawn. The final dimension is the one that is perhaps most studied, namely endorsement. Its prototypical emotions involve states of feeling happy or sad, cheerful and irritable. Happiness, on Haybron's view, is a sort of psychic affirmation or flourishing that involves the positive responses of these three dimensions.

Our claim is that when we are trying to understand whether someone (even oneself) is doing well or badly, we typically consider information about her un/happiness to be relevant and, in fact, the main epistemic channel available. Hence, if you looked depressed, or extremely anxious, or extremely irritable, or just rather sad all the time, we would dismiss as likely untrue any claim to the effect that you are doing well, even if it came from you. This, however, is not to say that un/happiness responses are infallible guides, for they may well fail to be grounded as, for example, when our perceptions are not veridical or our psyche generally out of balance. ${ }^{\text {xix }}$

So far we have argued that a person's un/happiness is the main source of evidence for how well/badly she is doing. It follows that understanding what typically makes a person's un/ happy (what a person's un/happiness is a reaction to) should take us closer to understanding what constitutes this person's well-being. Our thesis is that un/happiness is a reaction to the perceived fate of our attachments. In what follows, we will most

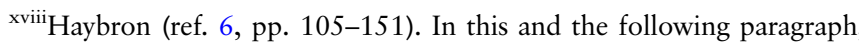
we draw heavily from Rodogno (ref. 1, p. 438).

${ }^{\text {xix }}$ These are issues treated in Rodogno (ref. 1, p. 443-444).
} 
briefly unpack this thesis before considering how it applies to the case of autism.

First, a few words about attachments. These are here understood as persistent forms of valuing that consist of patterns of dispositions including (i) cognitions, (ii) normative cognitions, (iii) affective responses and (iv) motivations. We may be attached to all sorts of things: persons, including oneself, values and ideals, including self-ideals, objects, activities and pursuits, including careers and hobbies. Hence, for example, if you are attached to a certain activity, say, basketball, which you pursue as either a hobby or as career, you will be attentive to information relative to it (ie, occasions for playing, teams now hiring, facts about other players) and will cognise some of this information in normative terms (ie, the fact that one of your favoured teams is playing in town is a reason for you to buy a ticket); you will also be emotionally affected in ways in which you would not otherwise be. Hence, you may feel pride at scoring a particularly important and beautiful basket or shame if your team lost badly against a poor opponent. Finally, you will typically be motivated to act in accordance to your normative cognitions and emotions (ie, buy the tickets, express your pride and do whatever it takes to avoid humiliating defeats).

Note that on this theory attachments do not as such constitute a person's well-being. They are rather preconditions for, both, the well-being and ill-being of a person. It is the fate of the attachment that ultimately determines or constitutes the person's well-being. Your un/happiness is a response to (signals) how you perceive your attachment to be doing. So if basketball playing is one of your attachments, you will be happy to the extent to which you perceive your attachment to be fulfilling your expectations, wishes and hopes. Your happiness is evidence, although defeasible evidence, that you are doing well, that is, that something that matters for you is indeed going in the right direction. Similarly, a career-threatening injury may cause you a lot of anxiety and perhaps depression. Your unhappiness will be evidence that you are not doing so well, at least when it comes to this hobby or career.

Closer study, via happiness, of the nature of human attachments will feed well-being relevant information into step 1 . In the next steps, theorists may then be able to systematise this material in a small number of categories or categorial goods, and, perhaps even those categorial goods familiar to Objective List theorists (attachments that are about deep personal relations or are primarily animated by the idea of enjoyment or achievement). This list of goods, however, would be built not on the basis of a priori intuitions about the nature of prudential goodness, and not even on the basis of people's desires, but rather through a process of interpretation and inference from the praxis of attachment.

\section{TOWARDS A NEURODIVERSE PHILOSOPHY OF WELL-BEING}

Given the bottom-up nature of the approach, the categorial goods delivered by this process should be understood as generalisations that may well apply to people across contexts, while falling short of being universal. On this approach, we should expect, and can allow, that some individuals or groups, given their peculiar histories and/or psychologies, may not (be able to) have the same kind of attachments as the majority of people in their society or even as the majority of groups across societies. We should in other words expect that contextual features such as the particular social and physical environment in which individuals find themselves as well as the psychological features of these individuals may have an impact on the nature and structure of their attachments. This is obviously good news for an approach to the study of well-being that wants to accommodate autism and neurodiversity more in general. On this approach, the theory would not be bound by neurotypical substantive a priori intuitions or patterns of desire about prudential goodness, nor would we be able to force onto our initial material perfectionistic views of 'human' nature that treat neurodiverse well-being as something other, if not lesser, than human well-being. ${ }^{\mathrm{xx}}$

While promising, this approach is still to deliver a clear answer to our practical problem: what model of the good life should parents of autistic children adopt in order to guide their well-being interventions? First, note that this approach can at least in principle fail to deliver anything that is general enough to be called a model. On this approach, the study of autistic well-being would begin by gathering information about which activities, structures, situations, relations, and so on tend to generate happiness and unhappiness. Those involved in this study can use all relevant means: directly observe autistic individuals in their daily lives; autobiographies; the accounts of those who live in close contact with autistic individuals and who may well have an idea about the happiness and unhappiness of the people they take care of; the relevant websites and other first-person accounts that can be certified as originating from autistic individuals. In what kind of activities do autistic individuals find security, engagement, flow? Is there something common to these activities? Is it a sense of structure or predictability?

It is an open question whether an enquiry such as this does in the end deliver material apt to systematisation into a model. We are quite confident, however, that the notion of unhappiness that we employ, with its emphasis on anxiety, depression and irritability, is particularly relevant here as it is an unfortunate thread in the life of many autistic individuals. ${ }^{x x i}$ On the basis of that, we speculate that the approach may therefore more likely deliver models of ill-being as opposed to models of well-being or the good life. That, however, would still count as progress. $^{\text {xxii }}$

This is all the more so when we keep in mind that, from a practical point of view, even models such as the Standard Model provide only very rough guidance. While pointing at a general

\footnotetext{
${ }^{\mathrm{xx}}$ Dan Russell (ref. 11, p. 5) comes close to sporting such a view. Russell insists that part of what matters about well-being, which he calls 'happiness', is being fulfilled as opposed to merely finding fulfilment. The former idea makes a reference to some notion of humanity, which, for example, essentially includes the capacity to love others. Hence: "Someone incapable of loving others [or emotionally childish]... might have a life that is fulfilling for him as it can be, given that unique make-up of his, but we would not point to his life as a good example of happiness. (It's certainly no life one would wish on a friend). If that is so, then we can understand happiness only by keeping in view that it is happiness for humans that we are talking about." So, if as a human being you happen to have a unique make-up that makes you 'emotionally childish', you will not be able to be fulfilled and have a good ('happy') human life. This is a kind of result that we hope our approach can avoid.

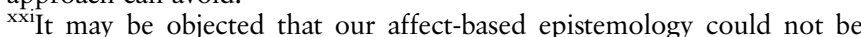
applied to an autistic population with a 40-65\% incidence of alexithymia (a subclinical condition characterised by difficulties in identifying and describing one's own emotional state) (in 'normal' population, the incidence is 10\%) (Berthoz and Hill; ${ }^{12}$ Hill et al. ${ }^{13}$ Yet, to our knowledge, there is no evidence that autistic individuals are less capable of affective states such as depression, anxiety and irritability. What is more, such states are generally observable by third parties, at least those that are acquainted with the subjects, and measurable by well-established psychometric tools. This is an advantage of this approach as it is applied to non-verbal and cognitively impaired autistic individuals.

${ }^{x x i i}$ See Mercier et al. $(2000)^{17}$ for a good illustration of the kind of qualitative evidence that we have in mind here.
} 
direction, they are silent about what each individual, given her specific (social, historical, psychological) circumstances, ought prudentially to choose or to have in order to live a good life. That is true also of more philosophically refined versions of these models, such as we could consider hedonism or Objective List theories to be. Hence, for example, on the assumption that hedonism were true, each individual would still have to figure out what things were sources of pleasure for her and, in fact, how large the positive balance of pleasure over pain in her life should be in order for her to have a good life. ${ }^{\text {xiii }}$ The details would be even more difficult to figure out if we worked under the assumption that there was an irreducible plurality of prudential goods. We would in that case have the difficult task of finding out what combination of these goods is good enough or best for one.

From a practical point of view, then, it is necessary to complement these models. What is missing is for each individual to conduct, and thereby have the freedom to conduct, his or her own 'experiments in living' xxiv This is a trial-and-error process in which, once again, happiness and unhappiness will be our guides. Whatever attachments we choose (or happen to have) may or may not turn out to be good for us. While in the act of choice, we can rely on the expertise of competent judges, that is, individuals who have experienced the options one is facing, and can distil useful and informed advice about them, but in the end, it is through the experience of happiness and unhappiness that we learn what particular attachments make prudential sense for each one of us.

These points apply pari passu to the case of autism. Even if we could arrive at some models, some significant details would have to be filled out by the individuals or by those who take decisions on their behalf, by way of experiments in living. In the case of autism, however, and for the time being, it is not possible to rely on the advice of competent judges because there are simply too few of them and because it is more difficult to make their expertise available to others. ${ }^{\mathrm{xxv}}$ What is more, we cannot simply assume that the normal structures and social praxes in place in a society can be trusted as helping to secure the child's (immediate and/or future) well-being. There will hence be much more experimenting with untrodden paths whose twist and turns are unknown and hence risky.

For example, and going back to the parenting of autistic children, rather than assuming that the child will simply be interested or uninterested in normal paths of socialisation as it happens in mainstream schools, if at all possible, there is going to have to be an exploration of the child's potential for socialisation in typical society. This would involve experimenting with such socialisation to various degrees while closely monitoring the child's levels of anxiety, irritability, if not depression.

Academic research, when properly conducted, may provide useful input here. In a recent study of autistic children aged 9-11 in mainstream schools, for example, Calder et al (ref. 15, pp. 309-10), observe that:

...there was much variability in the extent and nature of these children's friendships. Some children were considered central to high-status classroom social network and had stable reciprocal friendships verified by a number of sources. Others had links to one or two lower status members of the class group. Others still

\footnotetext{
${ }^{\text {xxiii }}{ }^{\text {Rodogno }}{ }^{1}$ expresses scepticism with regard to the possibility that the aggregate of a person's pleasure minus pain is a mental state, and one that is accessible to that person (or anyone else).

${ }^{x x i v}$ This expression comes from J.S. Mill's On Liberty (ref. 14, III.1).

${ }^{\mathrm{xxv}}$ The spread of internet communities for autists is a sign that things may be changing for the better in this department.
}

were on the periphery of their peer group, with some showing little interest in interacting with other children of their age. Importantly, no child with autism was completely socially isolated, unlike some other children in their classes. Motivation emerged as a key factor in parents' and teachers' perceptions of these differences. Children also appeared to benefit from direct support to develop their friendship skills.

Different children have different levels of involvement in friendship and the child's level of motivation pretty much explains why this is so. Yet, a parent may want to understand what one's child level of motivation is and whether this level should be taken as basic or is in turn to be explained by other factors, such as the child's development of social skills or the sensory issues that she may have and that may become a hindrance in the presence of several other children. ${ }^{\text {xxvi }}$ Answers to these questions may only be had by trying out several options, if indeed one is as lucky as having several options to choose from.

Interestingly, by studying what they call the quality of friendship, Calder et al conclude that, compared with their classroom peers of similar age and ability, children with autism perceive friendship in somewhat different terms. In particular, compared with their non-autistic peers, they rated their best friendships lower with regard to those dimensions of friendship that have to do with assistance and protection ('help'), and acceptance, validation and attachment ('closenesss'), but just as high as their peers with regard to dimensions such as 'companionship' (eg, "My friend and I spend a lot of our free time together"). In short, the picture that emerges from this study is a rather nuanced one: while most children with autism are socially interested, they are variably so, and their understanding of praxes such as friendship is not necessarily like that of their peers. The 'socialising' and 'being together' that adds to an autistic's quality of life might not quite have the same nature as what mainstream society would have it. When parents try to picture a model of the good autistic life, this is something they should consider.

\section{CONCLUSION}

By thinking about the issue of autism and well-being from the action-oriented perspective of a parent, we have learnt a few important lessons. For one, we were in a position to observe one significant shortcoming of much current philosophy of wellbeing. Most philosophers today take too uncritical a stance with regard to the well-being data that they go on to theorise. This fact is particularly lamentable when we consider that these very same philosophical theories form the theoretical background of much current empirical science of well-being. ${ }^{\text {xxvii }}$ This is not to say that the current approach is to be discarded but that it should be complemented by a more systematic epistemology of well-being and, in particular, by an autism-sensitive or neurodiverse-sensitive epistemology.

We have sketched a new approach to the study of well-being that takes its start in precisely such an epistemology. While on this approach we are not in a position to offer much substantive guidance to parents from the armchair, we are indeed in a position to tell parents what to do to obtain substantive knowledge about autistic well-being. In short, guided by their children and the competent judges' experience with happiness and

\footnotetext{
${ }^{x x v i}$ Calder et al (ref. 15, pp. 310-311) provide evidence against the claim that autistic children's verbal and non-verbal ability and their mentalising skills might be potential sources of variation in the extent to which these children can sustain friendships.

${ }^{\text {xxvii }}$ This is a point discussed in Rodogno. ${ }^{16}$
} 
unhappiness, parents will gain greater insight into what things can become significant attachments for their children and hence which 'normal' structures and praxes can and cannot be instrumental to or constitutive of their children's well-being.

Competing interests None declared.

Provenance and peer review Commissioned; externally peer reviewed.

\section{REFERENCES}

1 Rodogno R. Well-being between science and philosophy. In: Søraker JH, van der Rijt J, et al., eds. Well-being in contemporary society. Springer: 2014b:39-58.

2 Sinclair J. 1993. Don't mourn for us. Our Voice 1.3 also retrievable at http://www. autreat.com/dont_mourn.html

3 Han S, Northoff G, Vogeley K, et al. A cultural neuroscience approach to the biosocial nature of the human brain. Annu Rev Psychol 2013;64:335-59.

4 Aristotle. Nicomachean ethics. Trans. W.D. Ross. In: Barnes J, ed. The complete works of Aristotle, 2 vols. Princeton: Princeton University Press, 1984.

5 Sumner WL. Welfare, happiness, and ethics. Oxford: Oxford University Press, 1996.

6 Haybron D. The pursuit of unhappiness: the elusive psychology of well-being. Oxford: Oxford University Press, 2008.

7 Fltecher G. Objective list theories. In: Fletcher G, ed. The routledge handbook of philosophy of well-being. London and New York: Routledge, 2015.
8 Darwall S. Welfare and rational care. Princeton, NJ: Princeton University Press, 2002.

9 Mill JS. Utilitarianism. In: Robson JM, ed. (1963-1991), Collected works of John Stuart Mill. vol. X. Toronto: University of Toronto Press, London: Routledge and Kegan Paul, 1861. Retrieved 27 January 2016. http://oll.libertyfund.org/titles/165

10 Rodogno R. Happiness and well-being: shifting the focus of the current debate. South African J Philosophy 2014a;33:451-79.

11 Russell D. Human happiness. Oxford: Oxford University Press, 2012.

12 Berthoz S, Hill EL. The validity of using self-reports to assess emotion regulation abilities in adults with autism spectrum disorder. Eur Psychiatry 2005;20: 291-8.

13 Hill E, Berthoz S, Frith U. Brief report: cognitive processing of own emotions in individuals with autistic spectrum disorder and in their relatives. J Autism Dev Disord 2004;34:229-35.

14 Mill JS. On liberty. In: Robson JM, ed. (1963-1991). Collected Works of John Stuart Mill. vol. XVIII. Toronto: University of Toronto Press, London: Routledge and Kegan Paul, 1859. Retrieved 27 January 2016. http://oll.libertyfund.org/titles/165

15 Calder L, Hill V, Pellicano E. Sometimes I want to play by myself": understanding what friendship means to children with autism in mainstream primary schools. Autism 2013;17:296-316.

16 Rodogno R. Prudential value or well-being. In: Sander D, Brosch T, eds. Oxford handbook of value: the affective sciences of values and valuation. Oxford: Oxford University Press, 2015.

17 Mercier C, Mottron L, Belleville S. A psychosocial study on restricted interests in high functioning persons with pervasive developmental disorders. Autism 4, 2000. 


\section{JEE 'Autism and the good life': a new approach to the study of well-being}

Raffaele Rodogno, Katrine Krause-Jensen and Richard E Ashcroft

J Med Ethics published online May 12, 2016

Updated information and services can be found at:

http://jme.bmj.com/content/early/2016/05/12/medethics-2016-103595

\section{These include:}

References This article cites 5 articles, 1 of which you can access for free at: http://jme.bmj.com/content/early/2016/05/12/medethics-2016-103595 \#BIBL

Email alerting Receive free email alerts when new articles cite this article. Sign up in the service box at the top right corner of the online article.

Topic Articles on similar topics can be found in the following collections Collections

Psychology and medicine (222)

\section{Notes}

To request permissions go to:

http://group.bmj.com/group/rights-licensing/permissions

To order reprints go to:

http://journals.bmj.com/cgi/reprintform

To subscribe to BMJ go to:

http://group.bmj.com/subscribe/ 